\title{
8q22.1 microdeletion syndrome
}

INSERM

\section{Source}

INSERM. (1999). Orphanet: an online rare disease and orphan drug data base. 8922.1 microdeletion syndrome. ORPHA:178303

The 8q22.1 microdeletion syndrome or Nablus mask-like facial syndrome is a rare microdeletion syndrome associated with a distinct facial appearance. 